Egypt. Acad. J. biolog. Sci., 1(1): 65-69 (2009)

Email: egyptianacademic@yahoo.com

Received: 10/11/2009
C. Physiology \& Molecular Biology

ISSN: 2090-0767

www.eajbs.eg.net

\title{
Development of resistance in field strain of Aphis craccivora to the dinotefuran insecticides from the new class neonicotinoids and its effect on some enzymes content.
}

\author{
El-Sayed S. Mokbel and Azza I. Mohamed
}

Central Agricultural Pesticides Laboratory, Agricultural Research Center, Egypt

\section{ABSTRACT}

Resistance of cowpea aphid colony to the newest insecticide, dinotefuran was tested by selection pressure for 20 generations. Resistance ratio reached 148.8 fold in relation to susceptible strain. The $\mathrm{LC}_{50}$ value of the parent (first generation) was 5.39 ppm with slope value $1.06 \pm 0.53$ which mean that this strain was not homogenous to this insecticide. The value of $\mathrm{LC}_{50}$ increased slowly with selection pressure, reached $22.24 \mathrm{ppm}$ for the $10^{\text {th }}$ generation. Up to $15^{\text {th }}$ generation with the same selection pressure $\mathrm{LC}_{50}$ value increased to reach to $66.19 \mathrm{ppm}$ and reached to $230.71 \mathrm{ppm}$ in case of $20^{\text {th }}$ generation. Resistance ratio values in relation to susceptible strain, increased until the $10^{\text {th }}$ generation to 14.34 fold, and fastly increasing to 42.7 fold and 148.8 fold to $15^{\text {th }}$ and $20^{\text {th }}$ generation respectively.

Selection pressure produced some differences in total protein content and SDSprotein patterns. The analysis of esterase patterns obtained by the native- PAGE and by using $\alpha$ naphthyl acetate as a substrate which revealed a minor was measured.

Keywords: Resistance, Aphis craccivora, Dinotefuran, Neonicotinoids, Enzymes

\section{INTRODUCTION}

Unfortunately, many of conventional insecticides are harmful to human and beneficial organisms and caused ecological disturbance. This situation led to great demand for safe and more selective insecticides affecting specially harmful pests. One of these new approaches was the development of novel compounds acting selectively on some groups of insects by affecting biochemical sites such as respiration (diafenthiuron), the nicotinic acetylcholine-receptor (Neonicotinoids) or salivary gland of sucking pests (pymetrozine) (Ishaaya and Horowitz.1998).

Neonicotinoids have become one of the most extensively used insecticides for both crop protection and health applications. As with other classes of insecticides, resistance to Neonicotinoids is a significant threat and has been identified in several pest species (Zewen et al., 2003).

Also, neonicotinoids compounds effectively circumvent the known carboxylesterase, modified acetylcholinesterase (MACE) and knock-down (KDr) insecticides resistance mechanisms in aphid, Myzus persicae species, (Foster et al., 2003). So through this study we tried to elucidate the development of resistance of certain strain of Aphis craccivora to the novel compound nicotinic acetylecholine receptor agonists, dinotefuran which belong to the third generation of the new class: neonicotinoids.

\section{MATERIALS AND METHODS}

1- Insecticide used: Dinotefuran (MTI-446 20\% SG), nitroguanidine insecticides. 


\section{Chemical name:}

$N$-methyl- $N$ '-nitro-N"-[(tetrahydro-3-furanyl)methyl]guanidine.

\section{2-Insect Strains:}

\section{Laboratory susceptible strain:}

The laboratory susceptible strain of cow pea aphid, A. craccivora (koch) was originated from a field population, had reared for 30 generation ever since free from exposure to insecticides under laboratory conditions $\left(22 \pm 2^{0} \mathrm{C}, 70 \pm 5 \%\right.$ relative humidity and photoperiod $12: 12$ light : dark), the insects were kept on faba bean seedlings, Vicia fabae which grown in plastic pots. The pots with faba bean seedlings were maintained in another place without any exposure to insecticides.

\section{Dinotefuran resistance strain:}

This stain was reared described previously on faba bean seedlings and subjected to continuous exposure of the selected dinotefuran (MTI-446 20\% SG) under laboratory conditions. The selection pressure with insecticide used was carried out of various $A$. craccivora stages reared on faba bean to $\mathrm{LC}_{50}$ of the insecticide by spraying using 1 liter hand spray.

The strain has been remained under continuous selection pressure for about 20 generations. This strain was used for biochemical studies.

\section{3- Bioassay:}

The leaf-dip bioassay corresponded to that described by Moores et al., 1996 with slight modifications was used. Faba bean leaves were dipped in the aqueous solution of any of the tested insecticide for about 10 seconds and allowed to dry on paper towel. They were then placed upside down on an agar bed in small petri-dish (60 $\mathrm{mm}$ diameter). Ten apterous adults $A$. craccivora were placed on the treated leaf surface, while leaves dipped in water serve as controls. Three replicates batches of aphids (i.e,30 insects) were used per each insecticide concentration, and certain concentrations (4-7) being used for each insecticide. Petri-dishes containing aphids were kept in rearing chamber temperature until scored mortality.

\section{4 - Biochemical assay:}

Esterase patterns of samples of susceptible and dinotefuran- resistant strain were separated by polyacrylamide gel electrophoresis into two groups based on their ability to hydrolyze the following substrate: $\alpha$-naphthyl acetate.

\section{5- Data analysis:}

$\mathrm{LC}_{50}$, slope values and fiducial limits were estimated by using a software package "LD-P line", copyright of Dr. Ihab M. Bakr, Plant Protection Research Institute.

\section{RESULTS AND DISCCUSION}

\section{Dinotefuran resistant strain of $A$. craccivora:}

The cow pea aphid, A. craccivora were exposed to selection pressure up ward 20 generations. The $\mathrm{LC}_{50}$ values were obtained from toxicity regressions lines of the tested generations. The resistance ratio was used as an indication to the increasing of tolerance or resistance due to the selection pressure by the tested insecticide. The slope values of toxicity lines were taken as an indication of the degree of homogeneity of the tested population to insecticide. The obtained data are summarized in table (1).

These data showed that, $\mathrm{LC}_{50}$ of the parent (first generation) was $5.39 \mathrm{ppm}$ with slope value $1.06 \pm 0.53$ which mean that this strain wasn't homogenous to this insecticide. 
The value of $\mathrm{LC}_{50}$ increased slowly with selection pressure, reached to 22.24 ppm for the $10^{\text {th }}$ generation and the slope value also increased to $2.94 \pm 0.52$ which mean that this strain become to be homogenous. Up from $15^{\text {th }}$ generation with selection pressure the data showed high resistance increasing, and the value become $230.71 \mathrm{ppm}$, and the slope values started to decrease, which mean that the strain started to become non- homogenous.

Table 1: Development of resistance in the cow pea aphid, A. craccivora exposed to laboratory selection pressure with dinotefuran insecticide.

\begin{tabular}{|c|c|c|c|}
\hline Generation & LC $_{\mathbf{5 0}}\left(\mathbf{m g ~ L i t r e}^{-1}\right)$ & Slope \pm SE & Resistance ratio(fold) \\
\hline Susceptible strain & $1.55(1.22-2.30)$ & $2.78 \pm 0.64$ & - \\
Dinotefuran-selected strain: & & & \\
Parent & $5.39(2.45-9.55)$ & $1.06 \pm 0.53$ & 3.47 \\
$5^{\text {th }}$ generation & $10.27(7.34-16.42)$ & $1.66 \pm 0.35$ & 6.62 \\
$10^{\text {th }}$ generation & $22.24(18.70-27.07)$ & $2.94 \pm 0.25$ & 14.34 \\
$15^{\text {th }}$ generation & $66.19(48.02-90.71)$ & $1.90 \pm 0.42$ & 42.70 \\
$20^{\text {th }}$ generation & $230.7(158.53-384.98)$ & $1.30 \pm 0.31$ & 148.80 \\
\hline
\end{tabular}

Resistance ratio values in relation to susceptible strain, increased until the $10^{\text {th }}$ generation to 14.34 fold, and fastly increasing to 42.7 fold and 148.8 fold to $15^{\text {th }}$ and $20^{\text {th }}$ generation respectively.

Results obtained indicated that, resistance was grown slowly until the $10^{\text {th }}$ generation. This finding is completely agreement with Wang et al., (2002) who selected for a low level of resistance to imidacloprid, approximately 8 fold, in a line of cotton aphid, A. gossypii. Also, testing of field collected strains of tobacco whitefly, B. tabaci showed a slow but steady increase in resistance level to imidacloprid (Elbert et al., 2001), also agree with Prabhaker et al., (1997) who mentioned that high levels resistance to imidacloprid for silver - leaf whitefly, B. argentifolii was obtained after exposing whiteflies to imidacloprid over 32 generation, and reached resistance level of 82 fold compared with unselected strain.

Esterase patterns with $\alpha$ - naphthyl acetate:

Esterase analysis with native (PAGE) revealed 7 major bands with a high capability of hydrolyzing $\alpha$ - naphthyl acetate table (2) and Fig. (1). Comparison between susceptible and dinotefuran- resistant strain indicated that esterase patterns of susceptible consisted of five bands no.1,2,3,5and 7,with $\mathrm{Rm}$ values $0.068,0.193$, $0.310,0.539$ and 0.719 , while dinotefuran - resistant strain had more one additional band no. 4 with $\mathrm{Rm}$ value 0.432 . Comparing the susceptible strain with the field strain revealed two additional bands no. 4 and 6 and the disappearance of band no. 2 .

Scanning densitometric of $\alpha$-naphthyl acetate esterase patterns (table 2, fig 2) revealed that, the band no.3 represent the highest band concentration (27.02) in dinotefuran -resistant strain, while in susceptible stain the same band represent 22.73. The concentration of appearance band no. 4 in dinotefuran- resistant strain was $19.56 \%$, in contrast to susceptible strain the band no. 4 was absent.

Table 2: Rm values of esterase bands in susceptible and dinotefuran- resistant strain of A. craccivora (Koch) with $\alpha$-naphthyl acetate as substrate.

\begin{tabular}{|c|c|c|c|}
\hline Band No. & Rm value & Susceptible strain & Resistance strain \\
\hline 1 & 0.014 & + & + \\
2 & 0.130 & + & + \\
3 & 0.311 & + & + \\
4 & 0.448 & - & + \\
5 & 0.509 & + & + \\
6 & 0.636 & + & + \\
\hline
\end{tabular}


These results agree with Choi et al., (2001) who stated that, esterase activity was higher in imidacloprid- resistant strain than susceptible by 1.4 times. Also, O'Brien et al., (1992) found that, carboxylesterase activity was higher significantly in resistant aphid, A. gossypii strains to chlorpyrifos.

Generally, treatment the strain of A. craccivora by sub lethal doses from $\mathrm{LC}_{50}$ resulted in slight highly of $\mathrm{LC}_{50}$ from the first to the $10^{\text {th }}$ generation while after 15 generations, resulted in high values of $\mathrm{LC}_{50}$, where insecticide can be used for short period and stop its use for a while before applied again.
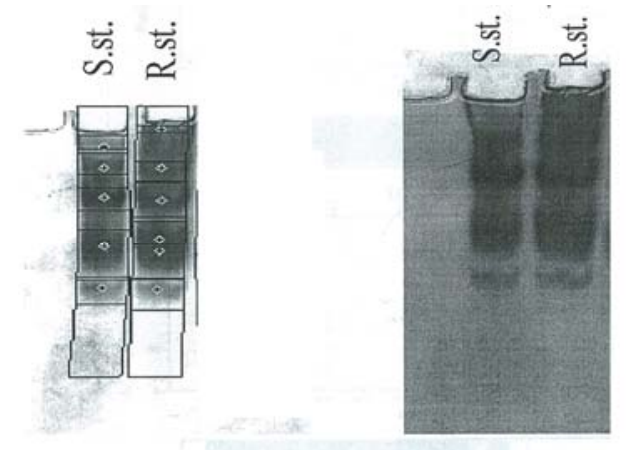

Fig.1: Polyacrylamide gel electrophoresis isozyme patterns in two tested strains of cowpea aphid with $\alpha$-naphthyl acetate.
S. st: susceptible strain
R. st:resistant strain
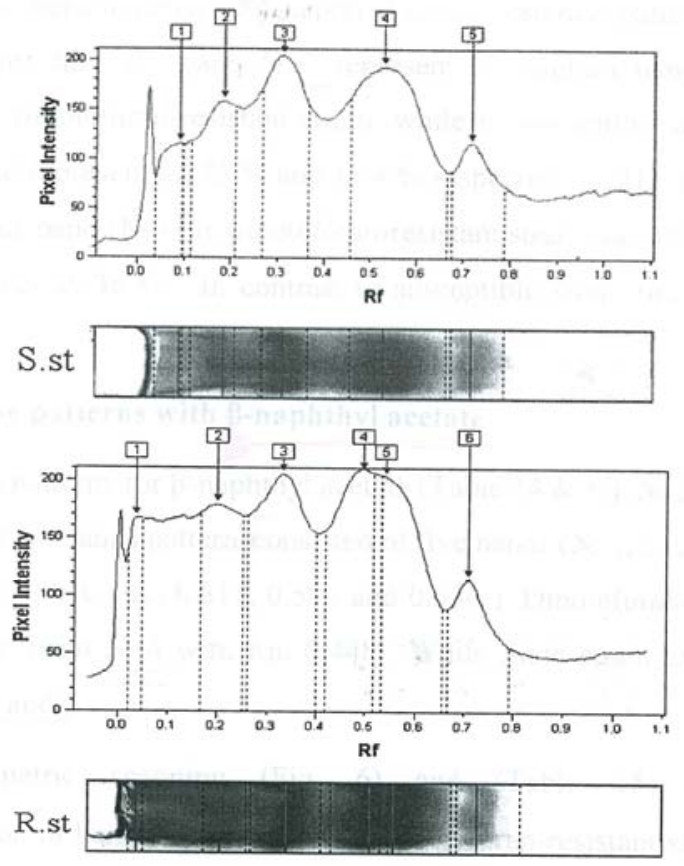

Fig. 2: Desitometric scanning of esterase patterns illustrated in Fig.(1).

S. st: susceptible strain $\quad$ R. st: resistant strain

\section{REFERENCES}

Choi, B.R.; S.W. Lee and J.K. Yoo (2001): Resistance mechanisms of green peach aphid, M. persicae to imidacloprid. Korean-Journal of Applied Entomology. 2001, 40:3, 265- 271. 
Elbert, A.; C. Erdelen; J. Kuhnhold; R. Nauen and H.W. Schmidt(2001): Calypso®, a new plant protection product for foliar application in fruit crops. Vortrage der Entomologentagung in Dusseldorf fur-allgemeine-und-angewandte-Entomolo. 2001, 13: 1-6, 223-226.

Foster, S.P.; I. Denholm and R. Thompson (2003): Variation in response to neonicotinoid insecticides in peach-potato aphids, Myzus persicae (Homoptera: Aphididae). Pest- Management-Science.2003, 59:2, 166-173.

Ishaaya, I and A.R. Horowitz(1998): Insecticides with novel modes of action: An overview. In: Ishaaya I.; D. Degheele (Eds) pp. 1-39, Insecticides with novel modes of action: mechanisms and application. Springer, Berlin-Heide-Iberg Newyork.

Moores, G.D; X. W. Gao; I. Denholm and A.L. Devonshire(1996): Characterization of insensitive acetylcholinesterase in insecticide-resistant cotton aphid, Aphis gossypii Glover (Homoptera: Aphididae). Pesticide-Biochemistry and Physiology. 56:2, 102-110.

O’Brien, P.J.; Y.A. Abdel-Aal; J.A. Ottea and J.B. Graves (1992): Relationship of insecticide resistance to carboxylesterase in Aphis gossypii (Homoptera: Aphididae) from midsouth cotton. Journal of Economic Entomolog. 1992, 85:3,651-657.

Prabhaker, N.; N.C. Toscano; S.J.Castle and T. J. Henneberry (1997): Selection for imidacloprid resistance in silver leaf whiteflies from the Imperial Valley and development hydroponic bioassay resistance monitoring. Pestic. Sci. 1: 419428.

Wang, K.Y.; T.X. Liu; C.H. Yu ; X.Y. Jiang and M.Q.Yi (2002): Resistance of Aphis gossypii (Homoptera- Aphididae) to fenvalerate and imidacloprid and activities of detoxification enzymes on cotton and cucumber. J.Econ. Entom. 95 (2): 407- 413.

Zewen,L.: J.H. Zhao, C.W. Yin, C.Z. Ling, W. Z. Hong and J.L. Cheng (2003): Selection for imidacloprid resistance in Nilaparavata lugens cross-resistance patterns and possible mechanisms. Pest Manag.Entomol.88:1164-1170.

\section{ARABIC SUMMARY}

\section{تطور صفة المقاومة فى آفة من الفول الحقلية لآحد المبيدات الحديثة (Dinotefuran) من عائلة وتأثير ها على بعض محتوياتها الأنزيمية.}

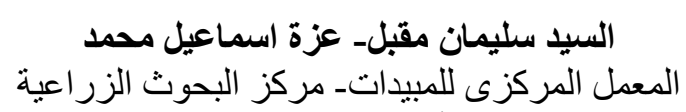

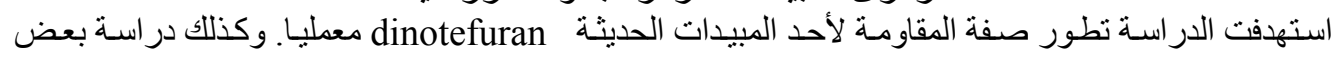

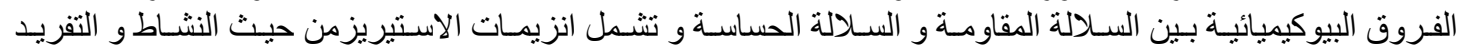

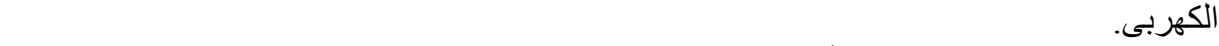

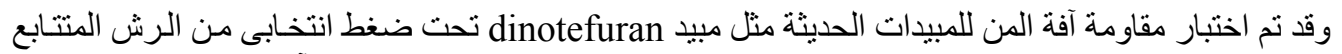

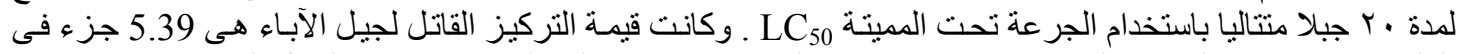

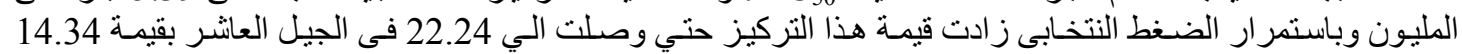

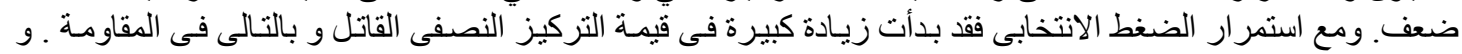

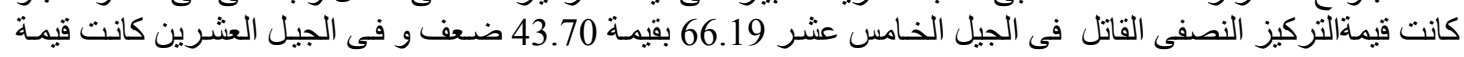

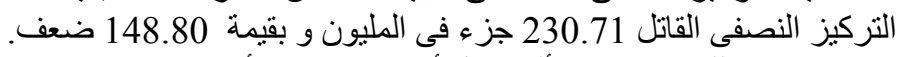

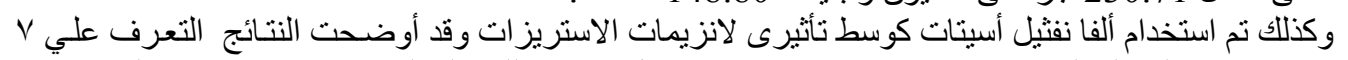

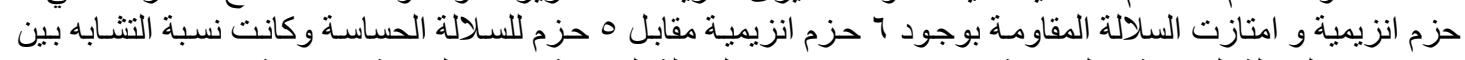

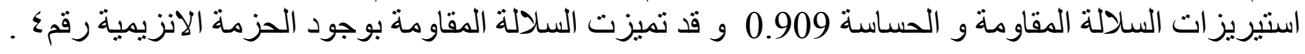

